\title{
La muerte, lo universal y la ruptura en la poesía de Raúl Gómez Jattin
}

Para iniciar el presente articulo, es necesario precisar los temas. El primero es un poema en memoria del escritor, el segundo son el establecimiento de algunos preconceptos a manera de introducción, el tercero es una pequeña muestra de la constatación de los tres referentes a tratar en el titulo, (la Muerte, lo Universal y la Ruptura en la poesía de Raúl Gómez Jattin), tomado del trabajo de grado para obtener el título de Licenciado en Lengua Castellana, y finalmente las conclusiones.

\section{Al poeta Raúl Gómez Jattin}

Andas por las carreteras

A tu espalda el peso de tus contemporáneos

y la pasión por la poesía

La soledad, la muerte y la locura son tus amigas

a las cuales cantas como a una musa

Viejo Raúl, cuánto añoro el haberte conocido en cuerpo sin dudar que te conozco a través de tu arte de dar vida a las palabras

Hubiese galopado a tu lado
Jhon Wilmar Rodriguez Diaz Licenciado en Lengua Castellana

Universidad Surcolombiana en el camino de soledad

Acompañando al son de mi guitarra tus canciones Escuchando las angustias y temores Comprendiendo el porqué de tu actuar.

Amigo conocido a través de la lectura

Me reconozco en tus letras

Porque cada una lleva algo de todos los hombres Y tú estás en cada una de ellas

\section{Descansa poeta}

Recita desde las praderas del cielo tus versos Llenos de sensibilidad y sentimiento

Que aquí en la tierra

los seres estaremos escuchando.

\section{Introducción}

En el sublime instante de abrir un libro, se deslumbra ante nosotros un universo, sin "fronteras, finales o comienzos..." 53 . Los caminos para su recorrido son solo opciones, jamás el único o el último. En él, el escritor, el

\footnotetext{
52 Este articulo constituye una sintesis de mi trabajo de grado presentado para optar por el título de Licenciado en Lengua Castellana de la Universidad Surcolombiana.

${ }^{53}$ Luz Helena Cordero Villamizar. Otra lectura de Gómez Jattin,
} 
lector y el crítico podrán encontrarse, al menos, en algún punto, gracias a la "geografía del texto". Pero de pronto, nunca vuelvan a reunirse en el bello momento que se aventuren en el mundo de la lectura. Es ésta una de sus majestuosidades.

Al ser el libro un universo permite diferentes perspectivas, en las cuales el lector puede manifestarse. Y aunque los teóricos han establecido los instrumentos para la aventura, siempre existe una opción más, fruto de los infinitos sentidos del escrito.

Los investigadores Carlos Altamirano y Beatriz Sarlo (1983), proponen tres aspectos, los cuales constituyen el blanco de la sociocritica: la ilusión referencial, en donde se "cree que el texto es el reflejo de algo". La ilusión del texto homogéneo, pensándose que el escrito "pertenece siempre a un género y que además tienen un único sentido que hay que descubrir"54. Y la ilusión del sujeto, afirmándose que el texto "es el producto de un sujeto, llámese escritor o lector, individual o colectivo" 55 . Alli podemos interpretar las obras como un fruto emocional o autobiográfico del autor.

Jan Mukarovsky (1992), propone que la obra literaria tiene una doble función: por una lado la función autónoma, compuesta a su vez por tres aspectos: 1. "obra- cosa": símbolo sensorial perceptible (el texto artístico). 2. "objeto estético" adecuado a la "conciencia de la colectividad y que corresponde a una representación históricamente determinada" 56.3 . Y la relación que existe entre la obra artistica y los fenómenos sociales.
De otro lado, la obra literaria establece la función comunicativa, tema del que trata la obra de arte sin guardar, precisamente, una relación documental con el tema designado. Por tal sentido, no es válido interpretar una obra como un documento histórico. La hibridación entre las dos anteriores funciones hace de la obra literaria un signo complejo.

Lo anterior indica que la poesía, y en este caso, la del poeta Raúl Gómez Jattin, enfatiza en su carácter autónomo. Expresa la ilusión referencial y la función autónoma y comunicativa, cuando en la obra se refiere a su pueblo y habitantes, sin hablar de los conflictos políticos y sociales de la época, ofreciendo un mar de significados y sentidos, provenientes del nivel semántico, del ritmo poético, alimentando, a su vez, la consciencia estética colectiva.

En cuanto a la autonomía del creador -el artista, el filósofo y sociólogo Pierre Bourdieu (1995) establece dos campos en que el artista debe moverse: el campo de poder como espacio de relaciones entre los agentes e instituciones que ejercen la acción para ocupar posiciones dominantes en los distintos campos de la sociedad. Y el campo literario: conjunto de toma de posiciones, en el cual el escritor va a ejercer con total autonomía su lugar. En este campo se presentan visiones heterónomas y autónomas. Las primeras son favorables al campo económico y politico, y el literato escribe para vender y de acuerdo con las exigencias del público. Las segundas, visiones autónomas o "arte puro", son las asumidas por artistas comprometidos con el arte, independientes, rupturales, que no escriben para el mercado, sino para expresar su visión del mundo.

${ }^{54}$ Altamiro. C. y Sarlo. B. Literatura/Sociedad. Buenos Aires: Hachete. 1983.

${ }^{55}$ Ibid.

${ }^{56}$ Jan Mukarovsky. "El arte como fenómeno sígnico" en: Jandová, 
A Raúl Gómez Jattin se le puede interpretar desde La ilusión del sujeto tratada por Carlos Altamirano y Beatriz Sarlo, ya que las obras son fruto autobiográfico y emocional del autor. También hace parte de la llusión referencial porque se refiriere a su entorno social, su pueblo. No obstante, también hace referencia a lo universal desde lo local, y desde su obra expresa la universalidad del arte; desde el punto de vista de Pierre Bourdieu, Gómez Jattin construye una obra en el campo literario, con visiones autónomas, que responde a su propio compromiso con la obra de arte.

Teniendo en cuenta lo anterior, se interpretarán los temas de la muerte y la ruptura en la obra de Gómez Jattin, y de manera transversal el tema de lo universal, ya que la muerte y la ruptura también hacen parte del mismo.

\section{La muerte}

En un rastreo de la poesía del autor Raúl Gómez Jattin, observamos una de las caracteristicas constantes en su obra; el tema de la muerte. Vista como aquella que implica el fallecimiento físico $o$, también, una especie de muerte en vida, cuando la existencia no tiene sentido y la pérdida de motivaciones nos llevan al desprendimiento terrenal.

Ya para qué seguir siendo árbol si el verano de dos años me arrancó las hojas y las flores Ya para que seguir siendo árbol si el viento no canta en mi follaje si mis pájaros migraron a otros lugares

Ya para qué seguir siendo árbol sin habitantes

a no ser esos ahorcados que penden de mis ramas como frutas podridas en otoño57
En el anterior poema "Pequeña elegia", el autor hace una analogía entre la vida de los seres humanos y la de un árbol. Sugiere simbólicamente que la vida pierde valor cuando el mal tiempo nos arranca las hojas y las flores y nuestros pájaros han migrado a lugares más hospitalarios. Es decir, no hay habitantes ni compañía, en palabras del autor, solo unas frutas podridas en otoño. De esta manera, cualquier persona estará muerta en vida, debido al desencanto y la desesperanza de la realidad. $O$. en otras palabras, se enmarcará dentro de la ausencia, a la que se refiere Gabriel Alberto: "La ausencia también la experimenta el hablante lírico con respecto al tiempo, al espacio y a los seres que lo rodean" 58 .

La muerte no sólo se da en vida, existe la muerte carnal consumada por diferentes razones, es el caso de la venganza, una de las más frecuentes justificaciones, por las cuales los hombres se creen con autoridad de privar a otros de la vida. En palabras de José Mora Ferrater "la muerte está presente en todo el ámbito de la naturaleza, es una presencia oculta que acecha las cosas y cae sobre el hombre"59 :

El agua del pozo está turbia pero refleja la cabeza rapada de la princesa atrida quien llena un cántaro para que beba Orestes Ya ha venido tres veces antes y el hermano se ha lavado la sangre de Clitemnestra La madre de ambos matada por los dos Todavía en su memoria resuenan los gritos de la muerta tratando de inspirar compasión

\footnotetext{
57 "Pequeña elegia" Amanecer en el Valle del Sinú. Antologia poética realizada por Carlos Monsiváis. Editorial Fondo de Cultura Económica. Bogotá, 2004.

${ }^{58}$ Ferrer Ruiz, Gabriel Alberto. Poética e identidad en Raúl Gómez Jattin. Versión online.http://apolo.uniatlantico.edu.co:8091/ uniatlantico/hermesoft/portal/home_1/rec/arc_7536.pdf

${ }^{59}$ Ferrater Mora, José La ironia, la muerte y la admiración, México: Cruz del Sur. 1946. P.
} 
Todavía en su memoria Electra guarda la faz descompuesta por el miedo y el dolor Mas la nieta de Atreo tiene sangre de crimen en las venas y facilidad para el olvido y aunque apenas han pasado unas horas de consumarse lo que ella ansió largamente la matricida sonrie a la imagen del pozo y piensa en el cuerpo esbelto de Pílades -el amante de Orestes- que el hermano le ha prometido como esposo y se toca los senos60

El poeta evoca el viejo mito griego narrado por Esquilo, donde la muerte es consumada por la venganza que realizan los hermanos matricidas. Castigan la muerte de su padre Agamenón , efectuada por Clitemnestra en complicidad con su amante, Egisto. Sus hijos Electra y Orestes, al enterarse del homicidio de su padre en manos de la madre, planean una muerte para la victimaria, la llevan a cabo, y en lugar de Electra estar afectada por su manera de actuar, piensa en el esposo que le ha prometido su hermano, cumpliendo su venganza sin ningún remordimiento.

La muerte, generalmente, cuando es por venganza es también ideada. Se lleva a cabo friamente, sin remordimientos de ninguna indole, se proyecta y calcula muy bien, para no cometer errores:

Medea afila los cuchillos en la cocina del palaciocon una fiera sonrisa torcida $y$ desenfrenadamente loca

con una intención implacable y asesina ya puestaa prueba cuando descuartizó e hirvió en una ollaa su padre el rey de la nativa tierra bárbara Hace tres días que envenenó los regalos que enviaraa su rival la desdichada princesa prometida de Jasón

Son tóxicos quemantes que destrozarán sus carnes traidos por Medea furtivamente desde la Còlquide

Ahora Medea -la de Euripides la asesina la de siempre-acabado el trabajo va de la cocina a la alcoba de tules transparentes y lecho altísimo como un altar y esconde los cuchillos bajo los cobertores blancos de lana virgen traída de Micenas y Rodas

Arregla su tocado de perlas y amatistas oscuras ante un gran espejo de plata que la refleja poniendo sobre la frente el cabello en cerquillo admirándose a sí misma con impavidez y despreocupación de lo terrible que trama alisando los pliegues de la pesada túnica cosida con hilos refulgentes de oro asirio Nada teme la de más allá del Helesponto Cuando sorprendió dormido al padre Todo lo tenía preparado y nada le falló Ahora las victimas tiernas que son sus hijos facilitan con su indefensión y amor por ella que los planes se cumplan como Medea piensa En la terraza la espera la carroza voladora tirada por dragones de fuego y de viento De pronto los brillantes ojos de pantera se encienden:

ha oído las voces conocidas de los niños Con movimientos seguros va en busca de los cuchillos

Los toma con rápida destreza Los oculta tras la espalda y espera 63

"Electra" Hijos del Tiempo. Antologia poética realizada por Carlos Monsiváis. Editorial Fondo de Cultura Económica. Bogotá, 2004.

"Uno de los padres de la tragedia griega.

${ }^{62}$ Guerrero Aqueo que participó en la guerra de Troya.

"l"Medea" Hijos del Tiempo. Antologia poética realizada por Carlos Monsiváis. Editorial Fondo de Cultura Económica. Bogotá, 2004. 
Medea planea sus crimenes perfectamente. Primero, da muerte a su progenitor sin tener la conciencia del daño que hacía; después, envenena los regalos que enviará á su rival, la prometida de Jasón y, finalmente, concibe con sangre fría la muerte de sus hijos, las futuras victimas de los cuchillos afilados con tanta destreza, para que no fallen en el trabajo a cumplir. Es un ser tan malvado, que mientras piensa en lo que va a hacer se sonrie, y aunque hay un tiempo entre el plan y los hechos para poder pensar y rehabilitar lo ideado, ella realiza su quehacer con frescura y cautela, esperando el momento preciso para dar muerte a sus descendientes.

Medea es un personaje que Gómez Jattin trae a colación, por estar presente en todas las edades y épocas del hombre.

Por medio de los personajes de la mitología griega que encarna Raúl Gómez Jattin en sus poemas, se vislumbran todos los hombres de la tierra, con sus buenos y malos sentimientos y sentidos hacia la vida, queriendo continuarla $o$, al contrario terminar con ella. El mito de Casandra también es uno sobre la traición, donde los seres se confian de los otros, es el caso de Agamenón quien toma la mano de Clitemnestra, sin poder percibir el mal que le acechaba.

La vida de las personas puede finalizar a manos de otros, pero también puede llevarse a cabo por nosotros mismos. Queriendo trasladar el espíritu a lo que aún no conoce:
(...)

Airoso en galope

levantó la mano armada

hasta su sien

y disparó:

suave derrumbe

del caballo al suelo

Doblado sobre un muslo

cayó

y sin un solo gemido

se fue a galopar

a las praderas del cielo

El ideal humano seria llegar a la muerte sin el miedo de la dicotomía vida- muerte. Sin ningún pudor, el suicida busca con tranquilidad y querencia, una pradera hospitalaria donde pueda continuar galopando, sin dejar la airosidad que tuvo en vida. Mientras otros luchan contra la muerte, conciben una manera de seguir existiendo, en este caso por medio de la palabra. Esta es la lucha de Scherezade:

Está enamorada del asesino que la obliga noche tras noche a exprimir su memoria de la ancestral leyenda multiforme y extensa para salvar por un momento su indefensa vida Y mientras cuenta y cuenta Scherezade el Califa la besa y la acaricia lujurioso y ella tiene que seguir entreteniéndolo contandoporque el verdugo espera

en cada madrugada

Está a merced de quien la oye emocionada pero no levanta la sentencia a muerte

El artista tiene siempre un mortal enemigo que lo extenúa en su trabajo interminable y que cada noche lo perdona y lo ama: él mismo

\footnotetext{
${ }^{64}$ "El suicida" Amanecer en el Valle del Sinú. Antologia poérica realizada por Carlos Monsiváis. Editorial Fondo de Cultura Económica. Bogotá, 2004.
} 
En los anteriores versos, el poeta es consciente de la batalla que libran algunos seres contra la muerte. El artista vence a la muerte, cuando da vida a través de la palabra para dejar su legado en la memoria la colectividad.

Con esta demostración, se puede apreciar la constante de la muerte en la obra de Raúl Gómez Jattin, especificamente en los "Hijos del Tiempo". Como su autor lo manifiesta, son poemas de la muerte, porque "todos los personajes han matado, van a matar o van a morir. Es un libro dedicado a la muerte. A su presencia angustiante durante toda la vida" 65

La universalidad de la obra de Jattin no sólo se manifiesta desde la remembranza de antiguos mitos, también trata temas universales como la muerte y otros que se expresan a continuación.

\section{Lo universal}

Lo universal hace referencia a lo que de manera irrenunciable nos compete a todos y nos involucra, sin importar la época en que se desarrolle. En la poesía de Raúl Gómez Jattin, lo universal se manifiesta cuando el autor, a través de sus escritos se vislumbra a sí mismo y a otros, no únicamente desde lo material, sino desde aquello intangible pero existente, es el caso de los sentimientos: la esperanza, el amor, el odio, la amistad, entre muchos otros, que aquí o en cualquier parte del mundo siempre se presentan de la misma manera. Un ejemplo de una expresión universal, es la desilusión manifestada por el Yo poético de la siguiente manera:
Ah desdichados padres

Cuánto desengaño trajo a su noble vejez el hijo menor el más inteligente

En vez de abogado respetable Marihuano conocido

En vez del esposo amante un solterón precavido

En vez de hijos unos menesterosos poemas

¿Qué pecado tremendo está purgando ese par de viejos? ¿Innombrable?

Lo cierto es que el padre le habló e n su niñez de libertad De que Honoré de Balzac era un hombre notable De la canción de la vida profunda Sin darse cuenta de lo que estaba cometiendo" 66

En el anterior poema, observamos lo universal cuando Raúl Gómez Jattin se permite hacer lo que cualquier hombre puede hacer: hablar de sí mismo. Podemos ver, entonces, al Jattin humano como era en su realidad, sin ocultar lo más mínimo de su vida: estudió Derecho mas no fue abogado, tampoco tuvo esposa, su amante, compañera e hijos fueron la poesía. En estos versos, visibiliza la desilusión de esos seres que esperaban de él un hombre diferente, un hijo normal al resto de descendientes, sin percatarse del ser único y propenso a la poesía que rompe paradigmas. Es el poeta un hombre como cualquier otro.

Continuando con los temas universales, Jattin recuerda las edades de los individuos: infancia,

${ }^{65}$ Fiorillo, Heriberto. O.p cit. P.57

"Desencuentros" Retratos. Antologia poética realizada por Carlos Monsiváis. Editorial Fondo de Cultura Económica. Bogotá, 2004. 
adolescencia, vejez, vida, muerte y el razonamiento de cualquier hombre en torno a ellas, en este caso, las del propia autor como ser universalizado:

En este cuerpo

en el cual la vida ya anochece

vivo yo

Vientre blando y cabeza calva

Pocos dientes

$\mathrm{Y}$ yo adentro

como un condenado

Estoy adentro y estoy enamorado

y estoy viejo

Descifro mi dolor con la poesía

y el resultado es especialmente doloroso

voces que anuncian: ahí vienen tus angustias

Voces quebradas: pasaron ya tus dias

La poesía es la única compañera

acostúmbrate a sus cuchillos

que es la única" 67

El paso del tiempo ha sido una preocupación del hombre, porque con su transcurrir vienen la vejez, el olvido y la muerte. Los seres de todas las culturas han buscado la eterna juventud para no enfrentarse al envejecimiento. Por ser el tiempo una angustia universal es del poeta también, demostrando cómo lo inquieta el trascurrir de la época y la aproximación a la vejez, y reafirmando que es la poesia su única compañera hacia el camino solitario, doloroso e inevitable de la muerte. Es también la huida y la presencia dolorosas que llenan el vacio del poeta.

El pasar del tiempo lleva de manera inevitable a la vejez $y$, en muchas ocasiones, cambia las personas interiormente, volviéndolas en su mayoría seres malvados o, peor aún, seres sin memoria $\mathrm{y} / \mathrm{o}$ reconocimiento por los otros o por sí mismos:

Lo más probable

es que seas como los otros

ignorante y mentirosa

No aquella que pobló mi infancia

No aquella de luciérnagas en los ojos

Querida

Cómo estás de cambiada

Lo más natural es que seas como ellos indolente y malvada

Lo más natural

No el endeble pájaro de verano

No las margaritas del jardin 68

En el anterior poema, Jattin poetiza a quienes en su infancia fueron seres agradables, bellos, llenos de expectativas, a quienes el pasar del tiempo los volvió lo contrario: ignorantes, indolentes, mentirosos y malvados. Por medio de personajes degradados por el entorno social, buenos en la infancia, ahora convertidos en engaños, el Yo poético critica la sociedad, como lo hizo el tuerto López 69 . De otro lado, el titulo "A una vecina de buena familia", encierra una ironía satírica con una fuerte critica social.

La sensibilidad de los poetas para desentrañar las temáticas del mundo de una manera única y enaltecedora, es un arduo trabajo donde se sufre por percibir y concienciarse de las injusticias, desastres y penurias de la vida:

Por qué va a entristecerte el no ser poeta

Terrible sufrimiento el serlo

Sagrado es verdad-

pero terrible

\footnotetext{
67 "De lo que soy". Del amor. Antologia poética realizada por Carlos Monsiváis. Editorial Fondo de Cultura Económica. Bogotá, 2004.

68 "A una vecina de buena familia" Retratos. Antologia poética realizada por Carlos Monsiváis. Editorial Fondo de Cultura Económica. Bogotá, 2004.

6) Poeta cartageneto
} 


\section{PAIDEIASuscalombiana 16}

Tú eres un hombre bello

como no he conocido

porque vives lo bello

No te amedrenta el no tener

una belleza más

entre las que posees

Ser poeta es más que un destino literario

Tú lo sabes

Entonces por qué -me pregunto-

esas flores de papel descolorido y sin gracia

a la salida de tu barrio de ensueño70

Raúl Gómez nos refiere en estos versos el sufrimiento del artista, pero también el bello trabajo que es serlo, ya que es una especie de dios creador de vida, de ilusiones y palabras únicas. Aun así al poeta lo entristece el mundo, siendo una constante del común de los artistas de los confines de la tierra. Jattin universaliza su tierra y su gente en la poesía, cuando presenta su entorno y pobladores, dando importancia y valor a lo ocurrido en su contexto más próximo, sin tener la necesidad de rebuscar temas para poetizar; sencillamente, identifica lo propio y de esta manera demuestra el amor por su tierra:

Laberinto de adioses que vieron una lágrima Sol Tanto sol que a veces he olvidado sus noches Sol sobre los tejados y los transeúntes presurosos Pero también sombra bajo el sombrero del cielo Sombra en las higueras del parque $\mathrm{Y}$ a veces dulce sombra en las palabras de un amigo

Laberinto correteado por mi niñez de siempre La de palomas moradas en el campanario y en las manos de los niños cuando Fátima la virgen paseaba su pureza increíble en una paloma de algodón del tamaño de una casa Y parecía sonreír $Y$ el discreto milagro de las palomas sueltas de nuestras manos iRecuerdan Zuni Sara Thelba Rosalba Manuel Maria Auxiliadora Narcisa Daniel Joaquín Susa Martha? ¿Recuerdan? Volaron todas hacia ella Y la arrullaron

¿Recuerdas Alba que estabas disfrazada de ángel y se te cayeron las alas?

$\mathrm{Al}$ pueblo lo divide un río que refresca la resolana y la memoria Y que es manso como los cereteanos buenos

Porque también hay de los otros

Allí amé dos veces al Amor

Y el Amor dijo una vez que sí

Y otra vez que no

Que ni para el putas

Alli tuve una casa de techumbre pajiza con agujeros en lo más alto por donde el viento se colaba trayéndome noticias del Universo

Allí tuve una familia que amaba el arte y la naturaleza

y que hoy muertos los viejos anda suelta por el mundo

Alli soñé escribir y cantar Soñé llevarme a Ceretè de Córdoba a otros lugares Deletreado en un blanco papel A que gentes de otros ámbitos conocieran sus noches estrelladas de espermas de fandangos cuando la Candelaria y esa alma gentil y bondadosa de ustedes mis amigos

${ }^{70}$ "Sin querer ofender". Retratos. Antologia poética realizada por Carlos Monsiváis. Editorial Fondo de Cultura Económica. Bogotá, 2004. 
que saben con una botella de ron blanco entre pecho y espalda prometer este cielo y el otro

Los amo más en el exilio

Los recuerdo con un sollozo a punto de estallar En mi loca garganta He aqui la prueba71

En los versos preliminares, Jattin habla de Ceretè de Córdoba, su pueblo. Lo describe claramente en la primera estrofa: un pueblo iluminado por el sol, la resolana y la inhospitalidad de sus habitantes monótonos. Es tan soleado, según la analogía del poeta, que se ha olvidado la noche, no obstante hay sombra en sus árboles y en las palabras de los seres cercanos. Este mismo pueblo fue donde aconteció su niñez, un vecindario como todos los de Colombia, católico, donde se hace tributo a los hitos cristianos. Luego habla del río que cruza a Cereté, el Sinú, y lo asemeja con los habitantes amables del poblado. Hace una retrospección y habla de él, de sus infortunios, de su hogar y del aprendizaje del Universo que halló en los libros. Soñó con cantar, escribir y universalizar su pueblo para que el resto del mundo supiera de su presencia, y de sus caritativos y afables oriundos, quienes con sus palabras construían mundos distintos a los existentes.

De otro lado, mientras el poeta recuerda con añoranza el perfil de aquella mujer, también arriban a su memoria los frutos de su tierra, junto con las influencias traídas por su madre desde el viejo continente. Siendo un personaje que llega de lejos a quedarse en un lugar donde encuentre la armonía. $\mathrm{El}$ amor entre hombres es un tema universal, nadie se pone al margen de los sentimientos creados por aquellos a quienes hemos elegido querer, de manera voluntaria y sin pensarlo.
Para finalizar, se transcribe un poema donde se evidencia el interés de Jattin por universalizar su aldea y expresar por medio de sus escritos la riqueza de sus gentes y paisajes. Anteriormente, se expresa lo universal como aquello que nos es común a todos, Cereté, aunque esté lejos a la vista de muchos pobladores también hace parte del mundo como un símbolo universal, como el centro del mundo, perceptible desde la universalidad de los sentimientos, entre ellos el amor hacia el propio terruño:

El jet rojo y mercurio aterriza te digo en un paisaje que me parece marciano Hay una carreterade asfalto entre algodonales

y sorgos azules y terracota

Fernando por el cielo te voy a llevar al cielo que es mi valle y sobre todo mi Cereté del cielo Un pueblo lindo con una cabellera tenue de nubes

blancas Una gente de muchas razas y colores con un Español adelgazado por la voz del río No tiene una belleza inmediatamente percibible aunque es notoria Hay que mirar su entera alma con detalle Hay gente esforzada y alegre Hay música en su viento $Y$ no muy lejos está el mar Turquesa líquida y amorosa Hay una iglesia de hermosura medioeval y un campo verde con flores de ilán-ilán en primavera y cocuyos en el follaje

Una semana santa de parranda y comidas espléndidas y juegos de póker y

arrancón y dominó

Pero la parranda verraca

es la del sol con la vida72

\footnotetext{
7 "Cereté de Córdoba". Amanecer en el Valle del Sinú. Antologia poética realizada por Carlos Monsiváis. Editorial Fondo de Cultura Económica. Bogotá, 2004.

72 "La parranda verraca es la del sol con la vida". Amanecer en el Valle del Sinú. Antología poética realizada por Carlos Monsiváis. Editorial Fondo de Cultura Económica. Bogotá, 2004.
} 
Respecto a lo anterior, Gabriel Alberto dice: "Es importante detenernos en los retratos escritos por el poeta por cuanto son perfiles basados en el recuerdo y la memoria del hombre y la cotidianidad Caribe; Gómez Jattin reconstruye una serie de personajes ligados a sus afectos y a su entorno" 73 .

\section{La ruptura}

Raúl Gómez Jattin hace ruptura no sólo en la forma, también transgrede los esquemas vigentes en la poesía colombiana del siglo XX. Busca su identidad, en "zonas que le permitieran ligarse con los origenes, la autenticidad"74, creando una obra poética sólida y original, la cual no distingue cánones de ninguna clase; lo más importante para el poeta es el sentido dado a su poesía, donde se devela él mismo.

Cómo no afirmar que Jattin rompe en la parte formal de la poesía, si observamos que en toda su escritura no existe un sólo signo de puntuación, ésta ruptura es una constante en la obra del autor; en ninguna parte de su lectura encontraremos un sólo signo de puntuación. Jattin no utilizó la puntuación porque desconociera su uso, paradójicamente lo hizo de manera consciente para romper con los parámetros establecidos. De lo contrario, cómo nos explicamos la manera en que el autor identifica el lugar donde debería ir el signo de puntuación, no graficándolo, sino iniciando el verso siguiente con letra mayúscula. El lector de esta manera identifica la existencia de la puntuación antes de la palabra escrita con mayúscula inicial: La falta de signos de puntuación es una caracteristica permanente en la producción escrita de Jattin, que no se había explorada en la poesía colombiana y que posteriormente ha sido adoptada, no por influencia del autor, sino por estilos de otros autores contemporáneos, es el caso del ya fallecido novelista portugués José Saramago. Esta particularidad en la escritura, exige otro tipo de lectores, unos menos anecdóticos, más perspicaces y conocedores de la musicalidad que emerge en la poesía.

De otro lado y teniendo en cuenta que Gómez Jattin no es el precursor del versolibrismo o la falta de métrica en la poesía, la asume y se convierte en una de las caracteristicas importantes referentes a la ruptura en su poesia. El versolibrismo es adecuado al gusto del poeta por la utilización de figuras retóricas, para darle más sentido y énfasis a lo dicho en los primeros versos. Una de estas figuras es la anáfora, utilizada con frecuencia en este poema:

Soy un dios en mi pueblo y mi valle No porque me adoren sino porque yo lo hago Porque me inclino ante quien me regala unas granadillas o una sonrisa de su heredad O porque voy a donde uno de sus habitantes reciosa mendigar una moneda $o$ una camisa y me la dan Porque vigilo al cielo con ojos de gavilán y lo nombro en mis versos Porque soy solo Porque dormi siete meses en una mecedora y cinco en las aceras de una ciudad Porque a la riqueza miro de perfil mas no con odio Porque amo a quien ama Porque sé cultivar naranjos y vegetales aún en la canícula Porque tengo un compadre a quien le bauticé todos los hijos y el matrimonio Porque no soy bueno de una manera conocida Porque no defendi al capital siendo abogado Porque amo los pájaros y la lluvia y su intemperie

${ }^{73}$ Ferrer Ruiz, Gabriel Alberto. Poética e identidad en Raúl Gómez Jattin. Versión online. http://apolo.uniatlantico.edu.co:8091/uniatlantico/ hermesoft/portal/home_1/rec/arc_7536.pdf

${ }^{74}$ Lasso, Luís Ernesto, Intento de Crítica concreta Sobre Poesia Colombiana. Servi- impresos. Neiva. 2008. 
que me lava el alma Porque nací en mayo

Porque sé dar una trompada al amigo ladrón

Porque mi madre me abandonó cuando precisamente más la necesitaba Porque cuando estoy enfermo voy al hospital de caridad Porque sobre todorespeto sólo al que lo hace conmigo $\mathrm{Al}$ que trabajacada día un pan amargo y solitario y disputadocomo estos versos míos que le robo a la muerte 75

El escritor Gabriel Alberto se refiere al anterior poema en las siguientes palabras: "se manifiesta a través de lo regional (provincia) de los acontecimientos cotidianos intimos. En "El Dios que adora" el poeta señala lo que es, por medio de sus acciones. Se expresa una filosofia popular en su simplicidad, filosofia que oscila entre el quehacer diario y el sentimiento u oficio de poeta" 76 .

Ahora no sobre la forma, sino en lo referente al contenido o fondo de la poesía de Jattin, quiso crear un sentido, denominado por el profesor Luis Ernesto Lasso, desacralizador: trabajó temas inusuales en la poética colombiana, uno de estos es el pansexualismo

La gallina es el animal que lo tiene más caliente Será porque el gallo no le mete nada Será porque es muy sexual y tan ambiciosa que le cabe un huevo Será porque a ella también le gustaque uno se lo meta Lo malo es que caga el paloPero es el momento más bacano y el orgasmo es de fiebre ¡Loco! Supersexo para mis seis años

A la paloma no le cabe Pero es lindo excitarla Y hacerse amigo de ella y hacer de ella La palomao sea del palomo el signo sagrado del Amor
Aquel a quien nombro cuando no me duele en demasía Virgo como un palomo pero penetrable

La pata es imposible La perra no deja y muerde La cerda sale corriendo La gata ni pensarlo Chévere la carnera Se queda quieta La chiva en celo es deliciosa

Se me olvidaba la pava en la alegria sexual sale a la calle como la perra a putear De las aves lo más bacano es el pavo Todos los pavos son maricas Lo aprietan

Claro que la burra es lo máximo del sexo femenino pero la mula lo chupa $Y$ la yegua es de lo mejor...Pero

La cocinera hace todo Se levanta la falda y lo trepa a uno a su pubis Te pone las manos en las nalgas y te culea en esa ciénaga insondable de su torpe lujuria de ancha boca

El que se ha comido un burro joven sabe que per angostam viam hay más contacto y placer de entrar con ternura por donde la naturaleza aparentemente no lo espera Pero que recibe en un júbilo que no le conozco a la hembra

Todo ese sexo limpio y puro como el amor entre el mundo y sí mismo Ese culear con todo lo hermosamente penetrable Ese metérselo hasta una mata de plátano Lo hace a uno Gran culeador del universo todo culeado Recordando a Walt Whitman

Hasta que termina uno por dárselo a otro varón Por amor Uno que lo tiene más chiquito que el palomo" 77

\footnotetext{
75 "El dios que adora". Retratos. Antologia poética realizada por Carlos Monsiváis. Editorial Fondo de Cultura Económica. Bogotá, 2004.

${ }^{76}$ Ferrer Ruiz, Gabriel Alberto. Poética e identidad en Raúl Gómez Jattin. Versión online. http://apolo.uniatlantico.edu.co:8091/uniatlantico/ hermesoft/portal/home_1/rec/arc_7536.pdf

77"Donde duerme el doble sexo" Del amor. Antologia poética realizada por Carlos Monsiváis. Editorial Fondo de Cultura Económica. Bogotá, 2004.
} 
Según Álvaro Bautista Cabrera ${ }^{78}$ el poeta innova en su manifestación plural del sexo. "Otra forma que se destaca para el exorbitado imaginario es el erotismo plural y casi cosmológico... Es una manifestación sin tapujos de sus relaciones homoeróticas -término que yo le robo a George Steiner-y del zooerotismo"79. Argumenta posteriormente que aunque ya había escritores que rondaban sobre el mismo tema, "Gómez Jattin va más allá. Lo suyo es el erotismo con una variedad de animales, agregados mediante una enumeración humorística, poco escritas, por lo menos en Colombia"80.

La sexualidad fue un tema tabú y aún lo sigue siendo en la poesía colombiana. El pansexualismo fue un tema más que novedoso en la poesía de Gómez Jattin, sobre todo por ser él su precursor, con la seria intención de mostrar el sexo sin reservas, rayando con las normas tradicionales de una sociedad conservadora.

Un tema común dentro del pansexualismo es la zoofilia, una tradición del pueblo caribeño, como lo afirma Eva Durán ${ }^{81}$ : "práctica extendida y muy común en las zonas rurales de la Costa Atlántica colombiana consistente en que los chicos en edad púber y adolescente se inician sexualmente utilizando a las burras". Jattin no pretende ocultar la tradición, al contrario la evidencia de manera poética. Es una forma abierta de describir su experiencia sexual.
Como lo expresa Gabriel Alberto, "en esos versos se evidencia la combinación de un lirismo con un lenguaje cotidiano prohibido...sin embargo la misma violencia en las palabras lleva a plantear que el hablante lírico pretende subvertir un orden, romper con normas morales y sociales..." Se sumerge en una relación sin límites con el mundo.

Cambiando de tema pero continuando con lo ruptural en Jattin, los alucinógenos o drogas psicoactivas, son tópicos universales tratados por distintos autores nacionales e internacionales. Lo nuevo en Jattin es su forma directa de hacer referencia sin rodeos ni ambigüedades a dichos temas marginados, es alli donde se manifiesta el carácter de su ruptura:

Del hongo stropharia y su herida mortal derivó mi alma una locura alucinada de entregarle a mis palabras de siempre todo el sentido decisivo de la plena vida

Decir mi soledad y sus motivos sin amargura Acercarme a esa mula vieja de mi angustia y sacarle de la boca todo el fervor posible toda su babaza y estrangularla lenta con poemas anudados por la desolación

De la interminable edad adolescente otorgada por la cannabis sativa diré un elogio diferente Su mal es menos bello Pero hay imágenes en mi escritura

77"Donde duerme el doble sexo" Del amor. Antologia poética realizada por Carlos Monsiváis. Editorial Fondo de Cultura Económica. Bogotá, 2004.

${ }^{78}$ Profesor de la Escuela de Estudios Literarios, Facultad de Humanidades, Universidad del Valle de Cali, Colombia y estudiante de doctorado de la Universidad Michel de Montaigne.

${ }^{79}$ Bautista Cabrera. Álvaro. Raúl Gómez Jattin. Las fronteras del rio sinù. Versión online http:// poligramas.univalle.edu.co/28/5Alvaro.pdf

"Ibidem.

${ }^{81}$ Historiadora y escritora cartagenera. 
que volvieron gracias a su embrujo enfermizo Ciertos amores regresaron investidos de fulgor eterno Algunos pasajes de mi niñez volcaron su intacta lumbre en el papel Desengaños

de siempre me mostraron sus visceras

Hay quien confía para la vida en el arte en la frialdad inteligente de sus razonamientos

Yo voy de lágrima en lágrima prosternado Acumulando silabas dolorosas que no nieguen la risa Que la reafirmen en su cierta posibilidad de descanso del alma No de su letargo

Voy de hospital en cárcel en conocidos inhóspitos como ellos Almas con cara de hipodérmica y lecho de caridad Entregándole mi compañía a cambio de un hueso infame de alimento Toda esa gran vida a los alucinógenos debo

La delicadeza de un alma no está casi en los que se apropia Sino en el desprecio de ese estorbo

sangriento cual banquete de Tiestes que la opulencia inconsciente ofrece vana y fútil ${ }^{82}$

No se refiere a los sicotrópicos con versos que lleven a suscitar la idea en el lector, sino que es explicita en su poesía la inclinación de los hombres por la alteración de los sentidos, a través de ayudas externas como son las drogas psicoactivas.

El lector también podrá encontrar aspectos tratados explícitamente por el poeta Raúl Gómez Jattin, como lo es el homosexualismo, abordado de igual manera por otros autores en nuestro país o de otros continentes. Lo relevante es que Jattin no tiene problema en poner a flor de piel esta temática en la poesía, lo hace de manera evidente, porque pretende poetizar sus propias inclinaciones:

Esta noche asistirá a tres ceremonias peligrosas

$\mathrm{El}$ amor entre hombres

fumar marihuana

y escribir poemas

Mañana se levantará pasado el mediodia Tendrá rotos los labios

Rojos los ojos

y otro papel enemigo

Le dolerán los labios de haber besado tanto Y le arderán los ojos como colillas encendidas

Y ese poema tampoco expresará su llanto"83

El poeta simboliza esta temática en un plano más común, siendo una realidad en la cual el hombre siempre ha estado propenso. Deja a un lado los prejuicios y los tabú, con los cuales ha sido visto este aspecto. Para profundizar en la armonia del develarse tal cual como es, representando su quehacer y sus costumbres.

\section{Conclusiones}

1. En la poética de Gómez Jattin se encuentra de manera transversal el tema de la muerte, en ocasiones poetiza su manifestación fisica, en otras la muerte del alma y su propio padecimiento. La muerte es desde Jattin, un estado infalible para el hombre, perpetuo en toda su historia.

\footnotetext{
${ }^{82 " E l o g i o ~ d e ~ l o s ~ a l u c i n o ́ g e n o s " . ~ A m a n e c e r ~ e n ~ e l ~ V a l l e ~ d e l ~ S i n u ́ . ~ A n t o l o g i a ~ p o e ́ t i c a ~ r e a l i z a d a ~ p o r ~ C a r l o s ~ M o n s i v a ́ i s . ~ E d i t o r i a l ~ F o n d o ~ d e ~ C u l t u r a ~}$ Económica. Bogotá, 2004.

${ }^{83}$ Un probable Constantino Cavafis a los $19^{n}$. Del amor. Antologia poética realizada por Carlos Monsiváis. Editorial Fondo de Cultura Económica. Bogotá, 2004.
} 
2. Jattin plasma en su escritura temas universales como el amor, la soledad, la angustia del paso del tiempo, los alucinógenos, entre otros. Por ser tópicos que promueven preguntas a los hombres de todas las edades, además son aspectos que le permiten al autor universalizarse. En el momento que el lector de cualquier parte y tiempo del mundo realice su lectura, se va a sentir identificado porque son elementos del común de la vida de toda la humanidad.

3. Desde la interpretación de Octavio Paz sobre la ruptura, se puede reafirmar que Raúl Gómez Jattin, es un autor ruptural, porque irrumpió en el curso de la tradición escritural colombiana desde los aspectos formales y de fondo de la poesía.

4. Según Octavio Paz, Raúl Gómez Jattin es un poeta moderno, porque fue ajeno y extraño a la tradición; irrumpió el curso de una manera heterogénea, e inesperada; desde su diferencia se opuso a lo tradicional.

5. Raúl Gómez Jattin fue un poeta moderno desde el punto de vista de Berman Marshall ${ }^{84}$ porque, al igual que escritores como Baudelaire, Dostoievski, Goethe, entre otros muchos, "Los mueve, a la vez el deseo de cambiar -de transformarse y transformar su mundo" ${ }^{85}$, a través de su vida y su arte.

6. El poeta Raúl Gómez Jattin no desligó la vida de su obra poética, su obra es una manifestación de su propia vida y la de todos los hombres. Por tal razón, sufrió de todos los estigmas sociales que afectan la sensibilidad de los poetas y, a su manera, contraproducente, desafiante y distinta, representó los artistas.
7. Raúl Gómez Jattin es un poeta autobiográfico y biográfico. En su obra muestra artisticamente inclinaciones sexuales, vida, pensamientos comunes a la humanidad. Además, el entorno, las gentes, los lugares caracterizándolos, abordando problemáticas sociales, mas no de conflicto politico.

8. En relación a lo planteado por Pierre Bordeau, Jattin es un poeta autónomo en varios sentidos: primero no escribe su obra de acuerdo con las exigencias del contexto histórico y quiebra conceptos éticos y estéticos de la literatura colombiana, implanta voces y lugares de su región a través de una estructura coloquial, cínica y humoristica, llena de significados y significantes.

\section{Bibliografia}

1. Altamiro. C. y Sarlo. B. Literatura/Sociedad, Buenos Aires: Hachete, 1983, p.

2. Arévalo, Milciades. Raúl Gómez Jattin, Hijo del tiempo. Entrevista. Revista Puesto de Combate. No 57. Bogotá. 1999

3. Bautista Cabrera. Álvaro. Raúl Gómez Jattin. Las fronteras del río Sinù. Versión pdf http:// poligramas.univalle.edu.co/28/5Alvaro

4. Cordero Villamizar, Luz Helena, otra lectura de Gómez Jattin.

5. Ferrater Mora, José (1946). La ironia, la muerte y la admiración, México: Cruz del Sur.

6. Ferrer Ruiz, Gabriel Alberto. Poética e identidad en Raúl Gómez Jattin. Versión pdf. http://

${ }^{84}$ Filósofo y escritor estadounidense.

${ }^{85}$ Marshall, Berman. Todo lo solido se desvanece en el aire 
apolo.uniatlantico.edu.co:8091/uniatlantico/ hermesoft/portal/home_1/rec/arc_7536

7. Fiorillo, Heriberto. Op cit., p. 252 .

8. Jan Mukarovsky. "El arte como fenómeno sígnico" en: Jandová. P.

9. Lasso, Luis Ernesto. Intento de crítica concreta sobre poesia colombiana. Servi-impresos. Neiva. 2008.

10. Monsivàis. Carlos. Antología poética. Amanecer en el Valle del Sinú. Editorial Fondo de Cultura Económica. 2004
11. Marshall. Berman. Todo lo sólido se desvanece en el aire. . P.

12. Paz Octavio. Los hijos del limo, vuelta. La Tradición de la ruptura. Editorial Oveja Negra. 1985.

13. Roster, Peter J. (1978). La ironía como método de análisis literario. La poesia de Salvador Novo, Madrid: Gredos.

14. Restrepo, Mauricio. La poética de la soledad en la obra de Raúl Gómez Jattin. Universidad Tecnológica de Pereira. 2007 